Paweł Mościcki

\title{
Snapshots of Intimate Encounters ${ }^{1}$
}

DO1:10.18318/td.2015.en.2.7

If it is true that as soon as philosophy declares itself to be reflection or coincidence it prejudges what it will find, then once again it must recommence everything, reject the instruments reflection and intuition had provided themselves, and install itself in a locus where they have not yet been distinguished, in experiences that have not yet been "worked over," that offer us all at once, pell-mell, both "subject" and "object." both existence and essence, and hence give philosophy resources to redefine them. Seeing, speaking, even thinking (with certain reservations, for as soon as we distinguish thought from speaking absolutely we are already in the order of reflection), are experiences of this kind, both irrecusable and enigmatic.

Maurice Merleau-Ponty²

There is no such thing as the relationship between text and image. There is no single, all-encompassing and permanently valid model of the mutual relationship

1 Funding for this article was provided by the Ministry of Science and Higher Education as part of the 2012-2014 National Program for the Development of the Humanities.

2 Maurice Merleau-Ponty, The Visible and the Invisible, trans. Claude Lefort, (Evanston: Northwestern University Press, 1968), 130
Paweł Mościcki

is a philosopher, essayist and translator. He works at the Institute of Literary Research in Warsaw, which is a part of the Polish Academy of Science. and for the journa View: Theories and Practices of Visual Culture. $\mathrm{He}$ is the editor of a book on Maurice Blanchot The Extreme Literature (Warsaw 2007) and the author of The Politics of Theater: Essays on Engaging Art (Warsaw 2008), Godard. Arcades Project (2010), The idea of Potentiality: The Possibility of Philosophy according to Giorgio Agamben (2013) and We Also Hove Our Past. Guy Debord and History As a Battlefield (2015). 
between language and the visual, which is why all of the many theoretical attempts at formulating such a connection are forever doomed to failure, however impressive the conceptual constructs supporting such a relationship may appear. Thus there exists no such thing as a relationship or connection between text and image that would not at once be the source and effect of a specific historical moment, a moment that not only links the two media in a unitary configuration, but would also define a certain stage in their historical development, their reciprocal association, and the manner in which they are anchored in reality.

Therefore, what we are left with is a certain historical nexus between image and text, a specific moment in which their mutual relationship is redefined in a contingent and transient manner, one that may, on occasion, also be historically significant and influential. The relationship between photography and literature should also be regarded as a strand in the broad history of these intimate connections between the image and the word. Their development has also been fed by moments of particular intensification that sometimes open up new and unknown vistas for potential juxtapositions. Such moments of extraordinary intensity, in which speaking and looking become so consubstantial that they cast new light onto each other and crystallize into new configurations, may be called - to borrow a phrase from the classic essay by Gotthold Ephraim Lessing - "fruitful moments." In his famous Laocoon: An Essay on the Limits of Painting and Poetry, Lessing writes that when attempting to portray in a painting or sculpture a strong expression of emotion, as in the case of the work of art referenced in the title, it is most important to choose the fitting fruitful moment:

Since the artist can use but a single moment of ever-changing nature, and the painter must further confine his study of this one moment to a single point of view, while their works are made not simply to be looked at, but to be contemplated long and often, evidently the most fruitful moment and the most fruitful aspect of that moment must be chosen. Now that only is fruitful which allows free play in the imagination. The more we see, the more we must be able to imagine; and the more we imagine, the more we must think we see. But no moment in the whole course of an action is so disadvantageous in this respect as that of its culmination. There is nothing beyond, and to present the uttermost to the eye is to bind the wings of Fancy, and compel her, since she cannot soar beyond the impression made on the senses, to employ herself with feebler images, shunning as her limit the visible fullness already expressed. ${ }^{3}$

3 Gotthold Ephraim Lessing, Laocoon: An Essay on the Limits of Painting and Poetry, trans. Ellen Frothingham (Mineola: Dover Publications, 2005), 16. 
What is key in Lessing's deliberations is not just the observation that one must capture or freeze the subject's expression at a specific moment, but his emphasis on the temporal precision required by the decision. The fruitful moment should thus be distinguished from the culminating moment of the action. ${ }^{4}$ The latter intensifies the pathos of the experienced suffering or joy to such a degree that no room is left for the imagination: the depiction is frozen in its literal form. The fruitful moment, on the other hand, allows us to read into the corporal expression of the depicted figures with the simultaneous use of our sight and imagination, the fluid combination of which reveals to us the desired depiction of emotions. This, however, places us simultaneously in two points in time: the one in which the experienced affect is the strongest, and the one we actually see once it is limited, but which can thus refer to our imagination of what just happened. The right way of depicting emotion, the choice of the fruitful moment, thus relies on the true art of skillful delay, the capturing of the moment that unfolds i m mediately after the culmination, when its traces are still legible, but it is no longer directly present.

Another example illustrating the creative intensification of time is that of Henri Cartier-Bresson's "decisive moment." The term describes a certain convergence between the attention of the photographer, his compositional skills, and the complex situation in which he has found himself and which he is attempting to portray. The goal of the photojournalist, Cartier-Bresson says, is to capture on photographic film a situation and a configuration of figures that would convey the essence of the event without resorting to elaborate stories and creating a serial composition. This, however, requires the photographer to momentarily fuse with the world; not just with the rhythm of what is happening, but also with the deeper logic of the events:

To me, photography is the simultaneous recognition, in a fraction of a second, of the significance of an event as well as of a precise organization of forms which give that event its proper expression. I believe that, through the act of living, the discovery of oneself is made concurrently with the discovery of the world around us, which can mold us, but which can also be affected by us. A balance must be established between these two worlds - the one inside us and the one outside us. As the result of a constant reciprocal process, both these worlds come to form a single one. And it is this world that we must communicate. ${ }^{5}$

4 Ibid., 15 .

5 Henry Cartier-Bresson, The Decisive Moment (New York: Simon and Schuster, 1952), 42 
While Lessing argues that capturing emotion in the fruitful moment requires a slight yet skillful delay, in Cartier-Bresson's view, to capture the essence of a situation, one must converge perfectly with reality.

One could say that the story of the relationship between photography and text is marked by the rhythm of repeated moments of particular intensification, real events that redefine their mutual connection. The category of the event - a concept important to the leading 2oth century philosophers, including Martin Heidegger, Jacques Derrida, Gilles Deleuze, Jean-François Lyotard and Alain Badiou - is, as Martin Jay writes, essentially a phenomenon "possessing a multiple time [...] preserving traces of an unfulfilled past or signaling the emergence or at least the promise of a radically new future." 6 In the context of the relationship between different media, an event can mean two different yet not necessarily exclusive instances. First, it is a kind of breakthrough in the social, political or individual sense, that forces those attempting to react to it to conceive of a new type of connection between the photograph and the text, and thus it demonstrates to them that in their desire to remain "faithful to the event,"7 they can no longer persist in the configuration that existed previously. Second, it is the shift in the model of visual and textual constellations that can itself become the event, as it commands us to think differently and establishes new structures of understanding and perception. In his criticism of the somewhat lofty vision of the event as a form of absolute difference that requires a radical conversion, Jacques Rancière states that this view imposes a "certain identification scheme; it creates something like a group of specialists, people capable of recognizing what is and isn't an event." ${ }^{8} \mathrm{He}$ adds: "For me, the possibility that an action, a walk along the street, a glance through a window, the screening of a film, people going out onto a boulevard, or a performance will be become an event is not subject to axiomatization." 9 This means that not only is the event contingent, but particular ways of speaking and looking (and their articulation) change as they are influenced by the event, and can even become events themselves.

These two visions of the event - something that is beyond capturing and something that emerges from its transformation - need not be mutually exclusive, which in turn means that each historical breakthrough, including

6 Martin Jay, "Photography and the Event," in Double Exposure. Memory and Photography, ed. Olga Shevchenko (New Brunswick: Transaction Publishers, 2014), 100.

7 Alain Badiou, Ethics: An Essay on the Understanding of Evil, trans. Peter Hallward (London: Verso, 2012), 41 .

8 Jacques Rancière, La méthode de l'égalité (Montrouge: Bayard), 117.

9 Ibid., 117. 
those pertaining to the relationship between the arts and different media, should be viewed as a veritable node of possibilities, breakthroughs, challenges and configurations. In his recent comments on Lessing's famous essay, Hubert Damisch admitted that its lasting validity entails the need to formulate a new theory of nodes (noeuds) which - in analyzing specific depictions and historical artifacts - would be preoccupied primarily with the codependencies between affect, the body and modules of representation, or, in his own words, "dispositives."10 It is only through the use of such a "node topology" that we can demonstrate, for instance, how individual affects, visual and textual sensibilities, and the history of photography and literature converge at a particular moment in history.

\section{The Dialectic of Photography}

The discrepancy between Lessing and Cartier-Bresson's concept of the moment of intensified vision can be applied to the discussion on the ontological status of photography. On one side of the argument would be all of those who see the photograph as an extension of reality, a mere representation of its traces that in no way distorts what it depicts. As Roland Barthes writes, succinctly summing up this tradition of thought, the noeme of photography is "that-has-been." What this means is that "the photograph is literally an emanation of the referent. From a real body which was there, proceed radiations which ultimately touch me, who am here."12 This is why, to Barthes, the essence of the photograph "is to ratify what it represents."13

But there exists another, equally strong tradition that sees photography, from its very inception, not as a perfect imprint of material reality, but as a kind of fundamental forgery of the human experience. To put it in more exact terms, it is the precision with which a photograph reproduces reality that makes it a tool for the mortification of that which, unavoidably, is not fully defined, literal and mechanical in our experience of the world. Among the supporters of this critical stance is Siegfried Kracauer, who argues that what every photograph essentially depicts is a past that was never there, i.e., one that cannot be recalled. It is a segment of a past reality that has been reproduced literally, but by doing so, it violates the rules of human memory.

10

11

13

\footnotetext{
See Hubert Damisch, Ciné fil (Paris: Seuil, 2008), 113-145

1 Roland Barthes, Camera Lucida: Reflections on Photography, trans. Richard Howard (New York: Hill and Wang, 1981), 77

2 Ibid., 80

Ibid., 85
} 
Memory, Kracauer writes, "encompasses neither the entire spatial appearance of a state of affairs nor its entire temporal course. Compared to photography, memory's records are full of gaps." 14 But this discontinuity is a product, rather than a symptom, of memory. Gaps in memory are necessary if we are to remember anything at all, if - as Kracauer believes, undoubtedly following in the footsteps of Bergson ${ }^{\mathbf{1 5}}$ - we always remember that which is currently relevant and useful to our own lives. Yet this also means that the fragmented tissue of our memory, like our own lives, is in a permanent state of motion, and is capable of dynamizing the past by repeatedly juxtaposing its recollections with our current situation. Photography, on the other hand, retains an accurate trace of a specific and random image of reality, thus blocking this motion and so, from the perspective of memory, it seems nothing more than an "assemblage of garbage."16

The difference between these two positions - personified here by Barthes and Kracauer, but held by many others - may be regarded as an unsolvable aporia, an internal contradiction to which photography is condemned, but it can also be treated as a point of departure for an entirely new perspective on the medium. Or, rather, not on photography itself, in its generality, but on its historicity or even its eventfulness, which, nevertheless, cannot simply be placed in opposition to its theoretical generality, but is derived from it, becoming at once its confirmation and its abolition. When looking at a photograph and considering what it actually depicts, Barthes and Kracauer see completely different things. The former perceives in it a material trace of reality, while the latter sees a sign of something we have never actually experienced. An attempt to find the most basic common ground between these two points of view would reveal an interesting "altercation of seeing," a certain kind of split vision which, at the very moment when it perceives something very real in a photograph, succumbs to an illusion and in fact gazes at a view that has been detached from the world by the photograph. We could therefore say that the same image installs a certain gap or pause in reality, and even places it precisely where we would expect it to adhere most closely to reality. It thus creates an artificial, excess moment in the time we experience - the fitting fruitful moment. In order to redirect this detached moment back into the stream of experience, to plug this gap in time, something other than the

14 Siegfried Kracauer, The Mass Ornament: Weimar Essays, trans. Thomas Y. Levin (Cambridge: Harvard University Press, 1995), 50.

See Henri Bergson, Matter and Memory, trans. Nancy Margaret Paul and William Scott Palmer (New York: Zone Books, 1988). 
photograph is necessary: words, for example, that will name some of its elements, will identify views, recall faces, or, on the contrary, deny any similarity and question our memories. It is only the word that can, by reinstating the history and experience behind a photograph, name the gap that once deceived and disoriented our gaze. The moment of naming - by its distinctness from the mechanical reproduction of the photograph - introduces something fundamentally new that thereby makes possible a new configuration of meaning that is a superstructure built on top of the photograph while also transcending its directness.

A photograph never operates outside the confines of context, which also encompasses different points of view and ways of naming things that that are used outside the scope of the photograph itself. If this were not the case, we would indeed be condemned to a permanent aporia between Barthes and Kracauer's views, between a belief in the photograph's faithful rendition of reality and the suspicion that the image has tainted reality with pretense and forgery. Most of the discussions on the nature of photography as a medium revolve around this age-old conceptual opposition. Yet the photograph always appears in a world that is already populated with other images, words, sounds, etc., with which it comprises part of a shared node of experience. It is precisely this context that anchors the photograph in a reality that it never fully represents nor absolutely distorts, as is also true of other media. It nevertheless possesses a certain capacity for eventfulness as it retains a piece of reality in a literal image, tearing the continuity of time and demanding the participation of the other dimensions of our experience. The words that respond to this demand can also, in certain instances, be forced to say something in a completely new manner and to address the image in a different way than usual.

In other words, a photograph's potential eventful moment can be extracted precisely by the fact that the image is always accompanied by language, with which it constantly reckons and with which it shares a more or less intimate relationship. Thus the noeme of photography would not be "that-has-been," but a silent question that one must answer without the aid of a script. And while most answers will take the banal form articulated by Barthes, in no way does this invalidate the potentiality contained in that moment. It is simply an attempt to answer the question of what we experienced, how we want to remember it, and what rules will govern its recording in the log of our entire experience. The relationship between the photograph and language is thus never an exclusive relationship between two media, but a node of existential, ethical and political dilemmas. When a photograph touches upon something that is particularly resistant to being inscribed in this context through the use of the language at our disposal, there emerges an opportunity for a true event 
that transforms our understanding of the world, precipitating a new way of explaining it in one, intense moment. If, as Thierry de Duve proposes, "with photography, we have indeed the paradox of an event that hangs on the wall"17, then this event binds the photograph with that which is external to it, thus reconfiguring the forms of our experience. This coexistence between language and the photograph was once aptly described by William Saroyan, who said: "One picture is worth a thousand words. Yes, but only if you look at the picture and say or think the thousand words."18

These reflections on the photograph's fruitful moment find a certain echo in an idea developed in recent years by Ariella Azoulay, who envisions photography as a space in which a kind of civil contract is entered into and renegotiated. In her writing, the Israeli scholar makes a distinction between "the event of photography" and "the photographed event." While the latter is simply a fragment of reality captured on film, the former is a kind of configuration of different elements that constitute the very action of taking a picture. These two dimensions are never wholly separate from each other, obviously, though the discourse of photography has often omitted the event of photography and focused instead almost exclusively on the photographed events. But as Azoulay argues, "every photograph of others bears the traces of the meeting between the photographed persons and the photographer." 19 In other words, every photograph depicts not just a certain fragment of reality, but also, indirectly, the very event of its creation: when, why, by whom and in what circumstances it was made.

The aforementioned civil contract is situated at the same level as the event of the photograph. What does it entail and who is responsible for compliance with this agreement? Azoulay often emphasizes that the contract she describes stems from the very nature of photography as well as from the historical and political determinants of its invention. Thus, on the one hand, the very existence of a photograph implies a certain tacit contract between those participating in the event surrounding its creation:

From the fact that in the photographic encounter itself there is no need for the formulation or signing of a concrete pact, we can assume there has been some kind of tacit prior pact or agreement between the sides that

17 Thierry de Duve, "Time Exposure and Snapshot: The Photograph as Paradox, in Photography Theory, ed. James Elkins (New York, London: Routledge, 2007), 109.

18 Quoted in Jefferson Hunter, Image and Word:The Interaction of Twentieth-Century Photographs and Texts (Cambridge, London: Harvard University Press, 1987), 6.

19 Ariella Azoulay, Civil Imagination: A Political Ontology of Photography, trans. Louise Bethlehem (London, New York: Verso, 2012), 21. 
ensures the present encounter: not merely a contractual agreement or ad hoc understanding, but a civil contract. ${ }^{20}$

The collective captured in the image, along with the broader community that participates in the event of photography, is immortalized at the moment of their encounter as something unique that can never be reduced to the specific socio-political divisions that they may, incidentally, cocreate or even support. This means that the photograph is a kind of space for alternative socialization, one that is always open to the possibility of transformation and negotiation. In other words, it provides an opportunity to participate in the process of political empowerment even to those who have been stripped of their rights in the social space. Thus it outlines the shape of a community that transcends the boundaries of any current government or system:

Anyone who addresses others through photographs or takes the position of a photograph's addressee, even if she is a stateless person who has lost her "right to have rights," as in Arendt's formulation, is nevertheless a citizen - a member in the citizenry of photography. The civil space of photography is open to her, as well. That space is configured by what I call the civil contract of photography. ${ }^{21}$

Yet Azoulay recognizes, and even emphasizes, the fragility of both the civil contract offered by a photograph and the citizenship that it can grant to the expropriated. Photographs depicting the pain of people who have been stripped of their rights and exposed to suffering can themselves become persecutors, while the act of taking a picture can certainly prolong and intensify the humiliation of those depicted in the image. The potentiality of the civil contract nevertheless persists, Azoulay says, despite photography's entanglement in the mechanisms of power and exploitation: "Even when this encounter occurs under the difficult conditions of distress or disaster, when a threat looms over or has already caused harm to the political space, as a space of plurality and action, the act of photography and the photographs it produces might, at least potentially, restore it."22 And as long as the photograph exists, the groups and individuals depicted in it, even those who are excluded from or

\footnotetext{
20 Ariella Azoulay, The Civil Contract of Photography, trans. Rela Mazali and Ruvik Danieli (New York: Zone Books, 2008), 101

21 Ibid., 81.

22 Ibid., $89-90$.
} 
victims of the social hierarchy, can demand their rights and express their own suffering and aspirations. The fragility of the photograph's civil contract, its incessant oscillation between actual violence and potential solidarity, reflects, in Azoulay's view, the fragility of all social ties, and - we may add - that of the relationship between the image and the text, with all their historical implications. The photograph thus participates in history primarily by releasing the hidden potential of the present, which the image simultaneously binds to and misses. "The photograph," Azoulay writes, "always includes a supplement that makes it possible to show that what 'was there' wasn't there necessarily in that way." ${ }^{23}$ Every act of photography renews the chance for a new configuration of the life of a community, a chance to remedy harm and to equalize opportunities. It assembles a certain constellation of people and things while preserving on the print the ever-real possibility of redefining their shared history and our perception of it through the photograph, inconsistent as this perception may be with the overt intentions of the image itself. ${ }^{24}$

In her writing, Azoulay frequently emphasizes another historical dimension of the photograph, namely that of its social impact not just as a technological novelty, but as a new social practice or even, one might say, a new way of practicing that which is social. The very process of its invention was an indication of the fact that there was no single inventor behind the technology, nor was it restricted by intellectual property rights; rather, it was a discovery that opened a space for the shared use of images of our world. ${ }^{25}$ The ontology of photography, as Azoulay asserts, is thus necessarily a political ontology, or even - thanks to the impact photography has had on our communities by its very presence - an ontology of the political:

The ontology of photography that I seek to promote is, in fact, a political ontology - an ontology of the many, operating in public, in motion. It is an ontology bound to the manner in which human beings exist - look, talk, act - with one another and with objects. At the same time, these subjects appear as the referents of speech, of the gaze and of the actions

23 Ibid., 90

24 In addition to her theoretical analysis of this situation, Azoulay continues to work on the archives documenting the Israeli occupation of Palestine, attempting simultaneously to find in them the dignity of the victims on the one hand and, on the other, the "right to not be an oppressor" on the part of those who enjoy full rights under an unjust political system. See Ariella Azoulay, From Palestine to Israel: A Photographic Record of Destruction and State Formation, 1947-1950, (London: Pluto Books, 2011), and Potential History: Photographic Documents from Mandatory Palestine (Wrocław: European Culture Congress, 2011). 
of others. My intention here is not to lay out an ontology of the political per se. It is, rather, to delineate the political ontology of photography. By this I mean, an ontology of a certain form of human being-with-others in which the camera or the photograph are implicated. ${ }^{26}$

The very practice of photography, its broad availability and democratic nature have changed the conditions of this coexistence to such a degree that it has become very difficult to discern between the dynamic of the civil contract of photography and the political dynamic as such. Our lives, Azoulay admits, is littered with potential events that reference the photographic contract: "In the contemporary era, when the means of photography are in the reach of so many, photography always constitutes a potential event, even in cases where the camera is invisible or when it is not present at all."27 In other words, we now live in a world in which anyone can find themselves in view of a lens at any moment, and being-in-a-picture has all but become the kind of existentiell or coexistentiell that being-in-the-world was to Heidegger. ${ }^{28}$

In the writings of Ariella Azoulay and in our own reflections above, an image of the photograph emerges as a nexus or node that links in itself diverse elements and distinct systems of experience. This image is not based on a simple referential relationship (successful or otherwise) between the picture and reality, but rather on a complex web of mutual connections and tensions between the photograph and the various dimensions of its exterior. Why then, instead of speaking of the print, the impression, the vera icon or, conversely, of the simulacrum and the shadow, ${ }^{29}$ do we not speak about photography in terms of a kind of nexus or node which collects, in a non-linear and non-hierarchical manner, entirely disparate systems into one image and then returns them in a similar fashion? In his well-known essay on the state of photography in an increasingly mediated contemporary world, John Berger evokes an image of the photograph as radiation that is closely tied to the memory and the laws by which it is governed:

26 Azoulay, Civil Imagination, 18

27 Ibid., 22.

28 See Martin Heidegger, Being and Time, trans. Joan Stambaugh (Albany: State University of New York Press, 1996). The category of the coexistentiell was introduced into the language of philosophy - based on a rereading ofHeidegger - by Jean-Luc Nancy. See Jean-Luc Nancy, Ėtre singulier pluriel (Paris: Galilée, 1996).

29 See Bernd Stiegler, Bilder derPhotographie: Ein Album photographischer Metaphern (Frankfurt: Suhrkamp, 2006). 
Memory is not unilinear at all. Memory works radially, that is to say with an enormous number of associations all leading to the same event. [...] If we want to put a photograph back into the context of experience, social experience, social memory, we have to respect the laws of memory. We have to situate the printed photograph so that it acquires something of the surprising conclusiveness of that which was and is. ${ }^{\mathbf{3 0}}$

To further develop this radial metaphor of the photograph, we could say that, in the most descriptive sense, the image works through a double movement. First, it collects within the frame and its associated situation a certain array of elements. One might describe this as the centripetal radial movement that captures, at a certain moment, the movement of the world in some more or less random configuration. This act has a certain kind of "decisiveness," to borrow a term from Berger, in its coupling of diverse elements into one photographic nexus. This category could serve as an apt depiction of the conviction shared by proponents of many divergent theories of photography regarding the technique's exceptional ties and particular adherence to reality. It could also help us transcend ossified oppositions such as inscription and reproduction, and reality and pretense that remain present in discussions of photography. The act of collection, in this case, refers both to the entirely material process of producing an image (using various techniques, digital or analog), as well as the various metaphors used to describe the act of photography, such as the civil contract discussed by Azoulay.

The other movement in the radial process of photography is one that we may describe as being centrifugal, as that which has been captured in the photograph is once again allowed to radiate outwards, freed from the moment that has been immortalized in the image. The photograph thus returns to the context from which it emerged, now saturated with meaning, subject to interpretation, processing, editing, etc. While the first step of the photographic act gathered diverse elements in order to capture them for a moment in a shared space, in the second, the finished photograph can once again transcend the limits of the frame and point to different parts of the world around it.

These two phases of the process by which a photograph is created and revealed constitute two inextricable elements of the same dialectic moment of a photograph's radiation; they mark the pulsating rhythm of the image. This dialectic may correspond with the alternating movements of mortification and vivification, abstraction and realism, immobilization and dynamic movement, etc. Because of the dialectic nature of this nexus, not only can we not separate one moment from the other, but nor can one exist without the 
other. The photograph can only bring something to life (itself included), for instance, thanks to the moment of capturing and "annihilation." Meanwhile the photograph itself always gathers things that are already entangled in its own independent dynamic, which the image attempts to record and capture to an equal extent. This radial dialectic of the photograph, its pulsating rhythm, also determines its historicity by the very nature of its participation in the historical process and its modus operandi therein. Finally, the dynamic nexus of contractions and expansions, centripetal and centrifugal movements, and the tying and untying of the bundle of elements demonstrates how photographs are related to other areas of our experience and to other media. Thus if John Berger argues in his essay that "the aim must be to construct a context for a photograph,"31 a context made up of words or other photographs, he does not articulate a task that could be the realization of some concrete movement for the improvement of photography as much as he names an ever-present dimension of the dialectic of the photograph: "Words, comparisons, signs need to create a context for a printed photograph in a comparable way; that is to say, they must mark and leave open diverse approaches. A radial system has to be constructed around the photograph so that it may be seen in terms which are simultaneously personal, political, economic, dramatic, everyday and historic." 32 This radial system exists and is an inextricable part of how a photograph works, even if, as Berger rightly observes, it does not make itself apparent in particular historical moments.

\section{The Great Crisis of Experience}

In his essay on art and the cultural contexts of narrative, Walter Benjamin formulated a famous thesis regarding the downfall of experience, which he linked to the transformations sparked in European societies by World War I:

With the [First] World War a process began to become apparent which has not halted since then. Was it not noticeable at the end of the war that men returned from the battlefield grown silent - not richer, but poorer in communicable experience? What ten years later was poured out in the flood of war books was anything but experience that goes from mouth to mouth. And there was nothing remarkable about that. For never has experience been contradicted more thoroughly than strategic experience by tactical warfare, economic experience by inflation, bodily experience

31 Ibid. 64

32 Ibid. 67. 
by mechanical warfare, moral experience by those in power. A generation that had gone to school on a horse-drawn streetcar now stood under the open sky in a countryside in which nothing remained unchanged but the clouds, and beneath these clouds, in a field of force of destructive torrents and explosions, was the tiny, fragile human body. ${ }^{33}$

In his commentary on these words, Jefferson Hunter, author of a broad and insightful book on the interaction between images and texts in twentieth century literature, states that similar symptoms could also be observed in the United States, where they were caused by the Great Depression of the 1920 s and ' 30 s, rather than by war:

It showed a substantial population of Americans that they could not depend on laboring as their parents had labored, or trust the same institutions, or even, when the drought began, look for the same rain from the sky. Contradicting politicians and communal wisdom alike, the Depression made history incomprehensible and left behind, as its legacy, tiny, fragile human bodies set in a countryside where nothing remained unchanged but the clouds. ${ }^{34}$

The deep financial crisis of the 1930 s affected not just the foundations of the lives of broad social groups in the United States, but it rattled the very framework of their world, casting doubt on the basic system of coordinates that allowed them to navigate that world. These circumstances required completely new forms of description, the establishment of new institutions and the redefinition of the social contract that lay at the foundations of the American state. Meanwhile in the aesthetic sphere, the Great Depression undoubtedly sparked the need, as Malcolm Cowley observes, for a "new art, one that has to be judged by different standards." 35 This art was the documentary, a genre that experienced intense growth on both sides of the Atlantic precisely in the 1930s. In the words of Olivier Lugon, author of a book that explores the "documentary style" that enjoyed great popularity following World War I: "the documentary marked a return to reality, a kind of challenged posed by the street in response to the pressure of the political and social events that enlivened the era. [...] It was not about a shift from one aesthetic to another,

33 Walter Benjamin, "The Storyteller," trans. Harry Zohn, in The Novel: An Anthology of Criticism and Theory 1900-2000, ed. Dorothy I. Hale (Malden: Blackwell Publishing, 2006). 
but about rejecting all manner of formal exploration and focusing instead on testimony and political activism." ${ }^{36}$ The photograph thus became a tool that enabled one to depict society, with all its complexity and divisive conflicts, and to open up new perspectives on other forms of art.

The documentary movement in the United States won the support of an enormous patron in the field of photography: the Farm Security Administration, an official government institution created as part of Roosevelt's New Deal. The agency, which operated from 1935 to 1944, was of course not tasked with promoting the art of photography. Its purpose was to save American agriculture by providing subsidies, supporting cooperatives that were hardest hit by the crisis, and starting new ones. The FSA was headed by the economist Rexford Tugwell, whose main goal was to lift part of the US economy from its knees and to protect farmers from the most dire effects of the Depression. Among the divisions that comprised the institution was the Historical Section, headed by Roy E. Stryker, whose tasks included promoting the agency through photography and, more importantly, documenting the sheer scale of the crisis and its social fallout for members of Congress and the general public. The section employed some of the country's leading photographers, providing institutional and financial support to such famous figures as Walker Evans, Dorothea Lange, Ben Shahn and Arthur Rothstein. ${ }^{37}$

The photographers employed by the FSA were thus tasked with depicting the suffering and poverty of American society to those who did not want to see it, but also to legitimize the actions of the government, which was making an effort to remedy the tragic situation. Photographs thus became "powerful agents in the awakening of social conscience," ${ }^{38}$ while their style could be described using simple slogans: "to persuade and convince." 39 The work conducted by the photographers, whose cameras documented the poverty of the farmers and their homes, the ongoing racial segregation, the social and class

36 Olivier Lugon, Lestyle documentaire. D'August Sander à Walker Evans, 1920-1945 (Paris: Éditions Macula, 2011), 53

37 See Lugon, Le style documentaire, 119. Regarding the work of the FSA, see Sidney Baldwin, Poverty and Politics: The Rise and Decline of the Farm Security Administration (Chapel Hill: University of North Carolina Press, 1968); Cara A. Finnegan Picturing Poverty: Print Culture and FSA Photographs (Washington, D.C.: Smithsonian Institution Press, 2003). Regarding the nature and development of documentary photography in America, see William Stott, Documentary Expression and Thirties America (New York: Oxford University Press, 1973).

38 Helmut Gernsheim and Alison Gernsheim, A Concise History of Fhotography (London: Thames \& Hudson, 1971), 257.

39 Beaumont Newhall, The History of Photography from 1839 to the Present Day, (New York: Museum of Modern Art, 1949), 19. 
conflicts, etc., was a kind of "short voyage to the land of the people"40 - one initiated and repeated by the government - in search of a new embodiment of the democratic subject that would emerge from the ruins of the old system. Their task was thus not to produce mere propaganda, but to include hitherto overlooked parts of society in the political community. The idea was to document how society's "other half lives," in the words of Jacob Riis, a pioneer of photojournalism who explored the world of New York's lower classes in the 19 th century, writing about them and documenting them with his camera. "Long ago it was said that "one half of the world does not know how the other half lives.'That was true then. It did not know because it did not care. The half that was on top cared little for the struggles, and less for the fate of those who were underneath, so long as it was able to hold them there and keep its own seat" 41 he wrote. The work conducted by the FSA was intended to change that, to a certain extent, by forcing one half of society to look at images documenting the lives of the other half and, in result, to accept the New Deal, which laid out the rules of a new social contract.

The entire undertaking was of course based on the belief that photography had the capacity to alter people's sensibilities, to directly influence not just their senses, but also their consciences. "Those who saw the suffering of others would immediately be compelled to help them out" $\mathbf{4 2}$, Vicki Goldberg wrote. One might say, referring back to Ariella Azoulay's observations, that the work of the FSA is an example of how official government institutions can, for better or worse, take control of the civil contract of photography and order the inclusion of new social groups and new areas of life in the sphere of representation. On the one hand, the institutions provide official endorsement of a fundamental shift in social sensibilities, on the other hand, they inscribe an unpredictable and potentially unlimited community of "citizens of photography" into institutional politics, thus making the community subordinate to the state apparatus. From this perspective, the difference between the persuasive and historical dimension of this undertaking is blurred, because by giving a community an image of its history - as did Matthew Brady during the Civil War, or Lewis Hine in his portraits of immigrants arriving in America - one also changes the community's image of itself very significantly. It is at once an act of historical documentation and political activism. ${ }^{43}$

40 See Jacques Rancière, Courts voyages aux pays du peuple (Paris: Seuil, 1990).

41 Jacob Riis, How the Other Half Lives (San Bernardino: ReadaClassic.com, 2010)

42 Vicki Goldberg, The Power of Photography: How Photographs Changed our Life (New York: Abbeville Publishing Group, 1991), 113. 
Another aspect of the FSA's work was the presentation of its photographic documentation in the press, most frequently in the form of prepared stories that combined photojournalism with traditional reportage. This was also the agency's response to how the context of the use of photography was changing with the appearance of such widely-read illustrated magazines such as Life and Look $k^{44}$. This period marked the rise of another phenomenon that is of particular relevance to this discussion, namely that of books that combined photographs and literary texts as part of a single project. Such publications often used the archives of the FSA or photographers associated with the agency as a source of visual content. But as Hunter points out, this kind of connection between the text and the image greatly exceeded the limits of journalism and propaganda material:

In practice, the most ambitious writers and photographers were unsatisfied with the pairing of the caption and illustration, and instead combined their work into "photo-texts" - composite publications evoking a landscape or recording a history, celebrating a community or mourning a loss. The words and images in photo-texts co-create their meaning on equal footing; thus a new genre was defined. ${ }^{45}$

Though they were often linked to the work conducted by the FSA and made use of various content from its archives, these books generally went beyond the historical and persuasive goals of the agency, thus demonstrating that the new configuration of image and text had become more than just a matter of aesthetic creativity, but also a requirement of that moment in history, with all its ethical and political aspects. The best known books in the genre among them AnAmerican Exodus: A Record of Human Erosion by Paul Taylor and Dorothea Lange, 12 Million Black Voices by Richard Wright, Land of the Free by Archibald Macleish, You Have Seen Their Faces by Margaret Bourke-White and Erskine Caldwell, and Let Us Now Praise Famous Men by James Agee and Walker Evans - are great tales about the human condition that are as sensitive to the historical intricacies of the collective experience as they are to the aesthetic

44 See ibid., 132 .

45 Hunter, Image and Word, 1. Regarding collaborations between writers and photographers in the United States, see Carol Schloss, In Visible Light: Photography and the American Writer, 1810-1940 (New York: Oxford University Press, 1987). Regarding the photo-text genre and, more generally, theoretical discussions on the relationship between the photograph and narrative, as well as on their practical applications in art in recent decades, see Marianna Michałowska, Foto-teksty. Zwiqzki fotografii z narracjq (Poznań: Wydawnictwo Naukowe UAM, 2012). 
nexuses of different systems of perception. Though they rarely challenge the assumptions of the FSA or the documentary style, these books exhibit a bit of what one might describe as activism within activism, a double loop that transforms this rather simple perspective in a compelling way. Each of these titles in its own way redefines the node in which photography and literature meet, simultaneously illustrating and co-creating the complexities of the historical moment that served as its context.

\section{Gestures of Intensified Time}

One of the best known and most widely read books to come out of the efforts to combine photography and literary texts was the opus You Have Seen Their Faces, published in 1937 by the photographer Margaret Bourke-White and the writer Erskine Caldwell. Both were well known within their respective fields at the time: Bourke-White for her extensive photojournalism work in such famous magazines as Fortune and Life, and for her pictures illustrating the development of industry in the USSR; Caldwell for his novels depicting the problems affecting the American South, including God's Little Acre (1933) and Journeyman (1935). The popularity of their collaborative book provoked much criticism, directed particularly at the exaggerated ease with which they combine image and text. Even Hunter - whose opinion of the authors' work is generally highly favorable - points out the book's numerous simplifications and the editorial pitfalls the pair succumbed to: generalization, excessive persuasiveness, and resorting to cheap effects. ${ }^{46}$ The objection against excessive attractiveness seems both unsophisticated and curious, particularly when leveled against books whose main purpose is not just to provide an argument or narrative, but also (perhaps more importantly) to produce a certain effect in the sensual as well as the intellectual and ethical sense. It appears that Hunter, in repeating the common criticisms of Bourke-White and Caldwell's work, assumes that the book ought to be discussed in terms of documentary honesty rather than artistic attractiveness, which cannot be clearly separated from the attractiveness of its individual components.

You Have Seen Their Faces deals primarily with the lives of the poorest Southerners, those making a living by growing cotton as sharecroppers. The idea is to juxtapose the historical and mythical dimensions of the South. On the one hand, the authors meticulously document the faces of their subjects, quote the stories they collected during their travels, and describe the social ties and economic problems in the region. On the other hand, they engage with the myth of the "Southern Extremity of America, the Empire of the Sun, the Cotton 
States," in which a particular spot on a map, constituting (like any other location) a cluster of diverse phenomena and situations, is treated exclusively as "the Deep South, Down South; it is The South." 47 Instead of making a clear division between these two levels, the authors play one against the other, thus building tensions that serve to illustrate a certain truth.

It is apparent that they also regard the South as a "worn-out agricultural empire," (p. 2) a region as real as it is symbolic. They behave not unlike anthropologists in distant lands, simultaneously fascinated by the curious nature of the natives and fully aware of their own roles and perspectives. In the very introduction to the book, Caldwell attempts a kind of critique of the colonial mindset manifested in the views of the South held by most Americans:

This is the place where anybody may come without an invitation and, before the day is over, be made to feel like one of the home-folks. Scientists with microscopes and theologians with Bibles come to the South to tell it what is wrong with it, and stay to buy a home and raise a family. [...] Mark against the South its failure to preserve its own culture and its refusal to accept the culture of the East and West. Mark against it the refusal to assimilate the blood of an alien race of another color or to tolerate its presence. Mark against it most of, if not all, the ills of a retarded and thwarted civilization. (p. 1)

These words are enough to reveal a certain ambivalent feature that is typical of Caldwell's writing, though no doubt remains as to his staunch views. Nevertheless, in his prose he mixes in equal measure his own criticism of Southerners (racism) with descriptions of the categories by which visitors from outside the region attempt to judge it. This minor vacillation in an otherwise expressive, and at times somewhat excessively agitational, text serves as a safety valve of sorts, a background that softens the focus a bit and prevents the main figures from appearing too sharp.

A similar point may be made regarding Bourke-White and Caldwell's treatment of the photo-text montage. It cannot be said that their book espouses one single method of combining photographs and text. The use of text, for instance, follows at least two different rules. On the one hand, the book present a rather concise analysis, organized into chapters, of the economic, racial and political circumstances surrounding the crisis, and its effects on the daily lives and living conditions of the sharecroppers. On the other hand,

47 Erskine Caldwell and Margaret Bourke-White, You have seen their faces (Athens, London: Brown Thrasher Books, 1995), 1. Subsequent references will be provided in parenthesis. 
the captions under Bourke-White's pictures, which often imitate the speech of those depicted in the images, form a fictitious internal monologue. Furthermore, an additional level of discourse, namely that of the actual quotes from stories collected by Caldwell during his travels throughout the South, accompanies his elaborate narrative, with which it is often juxtaposed and for which it sometimes serves as a painful illustration.

The prosopopoeia of sorts introduced by the authors in the captions accompanying the images, in lieu of a traditional journalistic format, demonstrate that their goal is not to feign objectivity. On the contrary: it is their intention to break with the anonymity of documentary photography by resorting to extreme personification. They simultaneously undermine any illusions of authenticity with regard to the statements made by the people depicted in the images: "The legends under the pictures are intended to express the authors' own conceptions of the sentiments of the individuals portrayed; they do not pretend to reproduce the actual sentiments of these persons" (p.X). Yet, if these words are in fact fictitious, it remains unclear whether we can believe the rest of the information supplied with the photographs, particularly the locations in which they were taken. Perhaps this is more of a reflection of the authors' fantasies about particular Southern states than of the actual conditions in the region. But what matters more than the authenticity of the captions and their correspondence to what is actually portrayed in the photographs is perhaps their general effect, which Hunter described thus: "[...] the images invite language. Furthermore, the style of the invited language corresponds with what is depicted." 48

Bourke-White and Caldwell appear to follow the recommendations of Walter Benjamin and other interwar left-wing theoreticians of photography, such as those associated with the magazine Der Arbeiter-Fotograf, who encouraged photographers to caption their images with a legend, thereby adding context and avoiding obviousness. In his 1934 essay The Author as Producer, Benjamin wrote that the production apparatus, the context in which a photograph functions, must be thoroughly overhauled, which, above all else, involves

bringing down one of the barriers, surmounting one of the contradictions which inhibit the productive capacity of the intelligentsia. What we must demand from the photographer is the ability to put such a caption beneath his picture as will rescue it from the ravages of modishness and confer upon it a revolutionary use value. And we shall lend greater emphasis to this demand if we, as writers, start taking photographs

48 Hunter, Image and Word, 73 . 
ourselves. Here again, therefore, technical progress is, for the author as producer, the basis of his political progress. ${ }^{49}$

Yet the authors of You Have Seen Their Faces seem unsatisfied with merely adding captions to the images, as the combination of photographs with the fictitious recollections of their subjects may readmit, through a back door, the impression of naturalness and fluidity that the legend, in Benjamin's view, would counteract. While Bourke-White did write a short epilogue for the book, she discusses in it mainly the technical aspects of her work, listing for instance the various lenses she used. She does not attempt to become a writer, just as Caldwell does not try his hand at photography, against the advice of Walter Benjamin - unless, that is, we count the terse descriptions intended to reveal, in a brief flash, some important aspect of the photographed scene. The natural quality of the photo-textual pairs is instead limited by Caldwell's main text - an extensive and cohesive study which, in contrast to the attractive photos and caption in the remaining parts of the book, demands attentive and careful reading.

The information and arguments thus provided require the reader to look at the caption and photo pairs in a different light. It is this double reading in the form of a single book that ostensibly enables us to follow the effects produced through quick editing while remembering the critical dimension of the whole project and assuming a serious, rational attitude toward its creators. On the other hand, the cohesive text itself is also made more concrete by its proximity to the photo-textual montage. Caldwell's text addresses three main aspects of the problems experienced by the inhabitants of the rural South. First, he states that their material and spiritual poverty was a result of changes in the economic system, as a result of which the entire burden was shifted onto the backs of the sharecroppers, while all the actual profits remained in the pockets of the landowners who cruelly leveraged their advantage over the farmers and relentlessly exploited their labor. In result, the sharecroppers worked on land they didn't own for humiliating wages and became entirely dependent on the landowners, while the lack of other options and the constant undervaluing of their work compelled them to be obedient even in times of hunger and extreme poverty. The sharecropping system developed in the South in the 1930 s was "ruinous because the system itself is not a collective venture but one of personal profit" (p. 46). Furthermore, these profits were available to a select few whose enrichment came at the cost of the destruction

49 Walter Benjamin, Understanding Brecht, trans. Anna Bostock (London: Verso, 1998), 95. For a similar argument discussed in circles associated with Der Arbeiter-Fotograf, see Lugon, Le style documentaire, $133-134$ 
of entire social groups, who were deprived of the basic means of human existence.

The second import issue that emerges from Caldwell's analysis is that of the economic origins of the racism that was rampant in the South and with which the region was invariably associated by the rest of American society. In You Have Seen Their Faces, hostility toward Blacks is seen as a consequence and a symptom of a broad range of socio-political tensions, which of course does not erase the moral responsibility of white farmers for the numerous acts of violence and persecution perpetrated by them against their fellow citizens. Caldwell describes the reasoning of a typical farmer in order to demonstrate the mechanism by which racial hatred is born:

Somewhere in the span of life he became frustrated. He felt defeated. He felt the despair and dejection that comes with defeat. He was made aware of the limitation of life imposed upon those unfortunate enough to be made slaves of sharecropping. Out of his predicament grew desperation, out of desperation grew resentment. His bitterness was a taste his tongue would always know. In a land that has long been glorified in the supremacy of the white race, he directed his resentment against the black man. His normal instincts became perverted. He became wasteful and careless. He became bestial. He released his pent-up emotions by lynching the black man in order to witness the mental and physical suffering of another human being. (p. 19)

The economic frustration of white farmers is buttressed on one side by the age-old traditions of white prejudice, and on the other by the fact that under the exploitative system that white farmers were also subject to, Blacks occupied the lowest tier and were literally reduced to the status of slaves. Their extreme humiliation leads white farmers to feel "that Negro tenant farmers do not need anything more than a bare living" (p.44).

Caldwell attributes a similar function - that of the symptom - to religion. For the Southern farmer

religion serve[s] as a release and escape. The sermons that are preached to him fulfill his desire for a vision of a different life. Once a week he can hear the minister promise him a new life in another world. It gives him something to look forward to during the other six days of hard labor when he and his family do not have enough to eat. (p. 39)

The futile repetition of the cycle of hard work and religious comfort creates a tension in the sharecroppers that can only be relieved in a spectacular 
fashion. Thus Caldwell, like Bourke-White in some of her pictures, portrays religion in its theatrical dimension, drawing comparisons to burlesque and hysteria:

The failure of the Church to preach its own convictions in the sharecropper country has resulted in its becoming a burlesque of religion. For this reason it is not difficult to understand why many of its houses are now places where once a week men and women go to elevate themselves into a state of religious ecstasy that enables them to forget their troubles. Men and women who writhe on the floor, shout until they have no voices left, go through various forms of hysterical behavior, do not do so merely because they believe they are Christians. They intoxicate themselves with a primitive form of religious frenzy that has its closest counterpart in alcoholic drunkenness. (p.40)

These descriptions correspond not only with photographs depicting the religious ecstasy of a congregation, but also with pictures in which BourkeWhite portrays a preacher intoxicated by his own voice and gesturing like an epileptic or a hysterical woman at Salpêtrière hospital. The captions beneath the pictures read: "Hurry, folks, hurry! Getting religion is like putting money in the bank" and "We've got a first-class God." (p. 34) By accompanying Caldwell's critical analysis with pictures whose legends suggest that the religious ecstasy is also equivalent to the excitement of commercial trade (the captions clearly indicate that the slogans are advertisements), the authors allow us to treat the word "symptom" as an entirely serious symbol containing, in a condensed form, conflicting elements of experience, if only because, as Freud and others argued, it helps one suppress a desire while simultaneously evoking it. 50

Freud attempted to define the nature of a hysterical attack thusly: "When one carries out the psycho-analysis of a hysterical woman patient whose complaint is manifested in attacks, one soon becomes convinced that these attacks are nothing else but phantasies translated into the motor sphere, projected on to motility and portrayed in pantomime." ${ }^{11}$ These hysterical movements and the intensification of bodily gestures that attempt to express something that cannot be expressed would serve as a fitting description of

50 Sigmund Freud, Inhibitions, Symptoms and Anxiety, trans. Alix Strachey (New York: Norton, 1977).

51 Sigmund Freud, "Some General Remarks on Hysterical Attacks," trans. Alix Strachey, in Sigmund Freud, The Standard Edition of the Complete Psychological Works of Sigmund Freud. Vol. IX (1906-1908) (London: Vintage, 2001), 229. 
the essence of Bourke-White and Caldwell's project, both in its socio-political or ethical dimension as well as the formal. Affects projected onto motility would correspond not only to specific, poignant poses by their subjects, but also to the radiation of photography and text, which are trying to produced a shared moment of intensity.

"The women waving hymn books were rushing up and down the floor in such a state of hysteria that several times I was nearly knocked over and the camera almost jarred out of my hands." 52 Bourke-White thus describes her encounter with the intensity of the symptom embodied by religious women in the South. These words aptly convey her approach to the portrayed phenomenon. She certainly does not behave like a disinterested researcher documenting, for the benefit of science, the symptoms of a disease while hiding her own dominance behind a shield of seriousness and the objectivity of academic processes. ${ }^{53}$ After all, she holds in her hand a small camera that protects her from nothing, though it may enable her to capture the moment of intensity in its culmination. It is then that we discover the fact that the subjects of the book nevertheless "are still people, they are human beings" (p.48), and the task of the authors is to extract a trace of that humanity, even if it is found in the bottom of a pit of squalor, mired in recurring symptoms of helplessness and escapism.

Bourke-White describes her work as a veritable hunt for moments in which suddenly, in a single gesture or nod, a spark of human dignity appears in her subjects and she will be ready to capture that moment immediately by firing her flash:

Flash bulbs provide the best means I know, under poor light conditions, of letting your subject talk away until just that expression which you wish to capture crosses his face. Sometimes I would set up the camera in a corner of the room, sit some distance away from it with a remote control in my hand, and watch our people while Mr. Caldwell talked with them. It might be an hour before their faces or gestures gave us what we were trying to express, but the instant it occurred the scene was imprisoned on a sheet of film before they knew what had happened.54

52 Margaret Bourke-White, "Notes on photographs," in Caldwell, Bourke-White You Have Seen Their Faces, 53

53 This approach was, to a certain extent, shared by Charcot and his collaborators, who "documented" episodes of hysteria suffered by women at Salpêtrière hospital. See Georges DidiHuberman, Invention de I'hystérie: Charcot et l'iconographie photographique de la Salpêtrière (Paris: Macula, 1982), 9-82.

54 Bourke-White, "Notes on Photographs," 51. 
A successful hunt sometimes resembles a kind of ruse used to steal the likeness of those whom one photographs. Bourke-White frankly admits that she owes most of her success in this field to the fact that the farmers in the South had never been photographed before and thus did not know how to challenge the artists about what they were doing. ${ }^{55}$ The search for a spark of humanity is certainly not without a bit of violence on the part of the authors, but its source is not, in this case, their desire to objectively record the symptoms of a social illness, but rather to capture them in their own, unique dynamic.

The key to You Have Seen Their Faces, however, appears to be the search - in the photo-textual pairings and their relationship to the background provided by Caldwell's cohesive analysis - for certain types of moments of intensification that themselves operate similarly to the symptoms, mainly because they contain at once several dimensions of the situations captured in the brief moment when the shutter is released and the flash fired, as well as several temporal systems, thus making the opposition between the culmination of the decisive moment (Cartier-Bresson) and the retrospection of the fruitful moment (Lessing) parts of the same anachronistic moment. Moreover, it is a search, in the hysterical discharges of the frustrated bodies, for symptoms of an era incapable of resolving its own contradictions and diffusing social tensions. Furthermore, it is an attempt to capture - in that same fruitful moment of expression - the instant in which new subjects step into the photographic community which Ariella Azoulay wrote about. Finally, Bourke-White and Caldwell appear to be forcing us to discern something more in these pictures and in the helpless gestures they portray - namely, "spasmodic signs of an agricultural revolution" (p. 43), foreshadowing and simultaneously blocking the possibility of taking "collective action against the institution of sharecropping." (p. 7) This overlapping of trends and time, the singularity of each gesture and the generality of its symptomatic reference can all happen precisely thanks to the invention of a specific temporal and spatial format for the coexistence of the image and text, in which not only do language and the photograph demand each other's presence, but so do disappointment and hope, criticism and empathy, the immediacy of a glance and the slowness of understanding incessantly refer to each other. 